\title{
Design of Experiments to Generate a Fuel Cell Electro-Thermal Performance Map and Optimise Transitional Pathways
}

\section{Abstract:}

The influence of the air cooling flow rate and current density on the temperature, voltage and power density is a challenging issue for air-cooled, open cathode fuel cells. Electro-thermal maps have been generated using large datasets (530 experimental points) to characterise these correlations, which reveal that the amount of cooling, alongside with the load, directly affect the cell temperature. This work uses the design of experiment $(\mathrm{DoE})$ approach to tackle two challenges. Firstly, an S-Optimal design plan is used to reduce the number of experiments from 530 to 55 to determine the peak power density in an electro-thermal map. Secondly, the design of experiment approach is used to determine the fastest way to reach the highest power density, yet limiting acute temperature gradients, via three intermediate steps of current density and air cooling rate.

Keywords - fuel cell; electro-thermal mapping; S-optimal design; cost-reduction; optimum transitional pathway.

\section{1-Introduction}

Hydrogen Fuel cells vehicles (FCV)s are part of the solutions considered to considerably reduce the carbon footprint in automotive applications (Sarioglu et al., 2014). However, due to the challenges associated with dynamics operations of fuel cells, and specifically heat and water management under non-steady state operation, optimisation of their operating parameters is of paramount importance to respond to abrupt performance changes.

Air-cooled open-cathode PEFCs have attracted increasing interest over the last decade. Unlike closed-cathode systems, self-breathing architectures offer the advantages of simple design and integration into systems, taking air directly from the atmosphere, hence particularly attractive for powertrain applications. Literature studies indicate passive open-cathode systems are typically limited to a maximum current density of $\sim 600 \mathrm{~mA} \mathrm{~cm}^{-2}$ (Bussayajarn et al., 2009; Hahn et al., 2004; Jeong et al., 2006a, 2006b; Schmitz et al., 2003) due to heat and water management issues, since no water is actively removed from the membrane, other than through evaporation (Fabian et al., 2010; Jeong et al., 2006a). Forced convection of air using fans improves performance in the open- 
cathode configuration, and enables much higher current densities to be attained (Kim et al., 2013; Rosa et al., 2007; Sasmito et al., 2012; Wu et al., 2009). It has been shown, through modelling and experimentation (Quentin Meyer et al., 2015b; O'Hayre et al., 2007), that increasing the air flow rate reduces the stack temperature, improves the membrane hydration and increases the limiting current density, so widening the operational boundaries. Furthermore, lowering the cell temperature in a controlled manner reduces the risk of heat spikes and thermal runaway, alongside with limiting the thermal stress on the membrane, which can lower the fuel cell performance, and drastically reduce the lifespan of the system(Sutharssan et al., 2016)

As such, an air-cooled, open-cathode fuel cell represents a system that generally benefits from having greater air supply from blowers (both reactant supply and cooling) at the expense of the increasing parasitic power required to deliver the air. Recent investigations have been carried out by the authors to map the current, temperature and water distribution in air-cooled, open-cathode fuel cells (Meyer et al., 2016; Q Meyer et al., 2015a, 2015b, Quentin Meyer et al., 2015a, 2015b), revealing that these parameters need to be considered in unison to understand how these complex systems operate. However, as the experiments are typically expensive in terms of planning, resource and time, a "smart" reduction of the number of experiments, yet with identical relevance in the interpretation is desirable.

Design of Experiments (DoE) enables a factorial experimental plan to be created which increases productivity by both minimising the number of test runs required and maximising the accuracy of the results obtained (Telford, 2007; Wahdame et al., 2009). As fuel cells have a wide range of material responses and operating conditions, DoE has been used extensively for analysis of material properties (Al-Saleh and Al-Zakri, 1998), improvement of bipolar plate design (Grujicic and Chittajallu, 2004; Rama et al., 2008), and optimisation of membrane electrode assembly composition (Akyalçın and Kaytakoğlu, 2008; Endoo et al., 2010) (including membrane type, platinum loading, Nafion impregnation in the electrode and gas diffusion layer assessment). DoE has also been used to improve the performance of fuel cell systems by maximising the power output and overall system efficiency (Chang et al., 2009; Torchio et al., 2005; Wahdame et al., 2007). 
The current work presents the results obtained by firstly applying a central composite design, then an S-optimal design plan, to reduce the number of experiments required, whilst obtaining a maximum power similar to the one of the large map (533 points (Quentin Meyer et al., 2015a)), yet with significantly less experiments. Further on, as the maximum power has been determined, the path to maximum power is optimised, via three intermediate steps of different current density and air flow rate (determined by the fan voltage) for a given time, in order to limit drastic temperature increases, yet reach optimum performance at the fastest rate possible.

\section{2- Experimental}

\section{Fuel cell test station}

The test system (Figure 1) supplies dry, non-heated, hydrogen (with a purity of $99.995 \%$ ) into the anodes and air is blown by three fans to the active cathodes and cooling channels (Meyer et al., 2013; Noorkami et al., 2014). A 5-cell, air-cooled, open-cathode fuel cell (Intelligent Energy, UK) is being used, generating a maximum power of $140 \mathrm{~W}$. The voltage to the fans, which provide cooling air and oxidant supply to the cathode, is controlled by a programmable power supply (3649A Agilent). The fuel cell is electrically loaded using a programmable load (Kikusui PLZ164). An in-house computer controlled system controls the air, hydrogen, cooling and electrical valves (LabVIEW, National Instruments), as well as recording and presenting data measured using a data acquisition card (PCI 6221, National Instruments), with a resolution of $30 \mu \mathrm{V}$ (i.e. $2 \mathrm{~V} / 2^{16}$ ). Ambient temperature, pressure (absolute) and relative humidity (RH) were measured, being of around $25^{\circ} \mathrm{C}, 1.02$ bar and $40 \% \mathrm{RH}$ respectively, during all tests. The software enables a maximum sampling rate of $3.33 \mathrm{~Hz}$. This was chosen as it enables to sufficiently capture temperature and voltage gradients, while avoiding data overflow.

The inlet hydrogen flow rate in through-flow mode was measured using a thermal flow meter (MassVIEW, Bronkhorst) to be $3 \times 10^{-5} \mathrm{~m}^{3} \mathrm{~s}^{-1}$. The stack is operated in quasi through-flow mode (high purge rate in order to avoid performance losses). Details on the stack cooling and active channel geometries has been provided in previous work (Meyer et al., 2013; Noorkami et al., 2014). A K-type thermocouple was inserted into the central cooling channel of the third cell (middle cell) in order to measure the temperature in the centre of the stack. 


\section{Experiment generation}

The electro-thermal dataset was generated by measuring the cell voltage, temperature and stack power, while controlling the current density and fan voltage (which regulates the air flow rate and cell temperature), varying the current density between 0 and $1 \mathrm{~A} \mathrm{~cm}^{-2}$ and the fan voltage between 4.5 and $14 \mathrm{~V}$. Each point was held for 30 seconds to reach pseudo steady state performance (Quentin Meyer et al., 2015a). In addition, the cell was allowed to cool down for 1 minute when the fan voltage was changed and the load reduced, making the total experimental time 8 hours with 533 datasets.

For the path optimisation, a further 330 experiments (72 paths using 4 different steps with the addition of the cooling step at the end), using the matrix generated by CAMEO were achieved in 4 hours, with different holding time $(0 \mathrm{~s}-174 \mathrm{~s})$, different current densities $\left(0.05\right.$ to $\left.0.83 \mathrm{~A} \mathrm{~cm}^{-2}\right)$, and different fan voltage (5.2 V to $10.42 \mathrm{~V}$ ). The cooling step was achieved by reducing the load to $0 \mathrm{~A} \mathrm{~cm}^{-2}$ and increasing the fan voltage to $11.5 \mathrm{~V}$.

\section{Modelling and Optimisation}

A commercial optimisation software (CAMEO, AVL, Austria) has been used for data fitting of the experimental matrix, generation of the two reduced matrices, construction of the robust neural network and $2^{\text {nd }}$ order polynomial models("Avl CAMEO - Calibration, All-in-one Powertrain," n.d.). It has also been used to generate the test-bed for the optimum pathway and predict the optimum pathway.

\section{3- Results}

First, the full experimental data matrix is used in order to generate the reference models. In the two following steps, DoE is applied with the target to get comparable results with a significantly reduced data set, using the central composite design (NIST/SEMATECH, n.d.) and the S-optimal design (Das, 2002; Lewis, 2009; Zloklikovits et al., 2008) approaches.

\subsection{Reduction of the number of experiments required to reach the optimum power}

First, the full experimental data matrix is used in order to get the reference models. In the two following steps, DoE is applied with the target to get comparable results with much less effort, 
using the central composite design (NIST/SEMATECH, n.d.) and the S-optimal design (Das, 2002; Lewis, 2009; Zloklikovits et al., 2008).

\section{Initial experimental matrix}

An electro-thermal performance map is first generated, as a function of the current density and fan voltage, to describe the variations of the cell temperature and cell voltage for 533 experimental data points. It is clear from this map (Figure 2 ) that the temperature largely affects the performances and cannot be neglected as a crucial parameter for operations. However, the determination of the optimum operating point (for example, the maximum power point may be the objective) can be more challenging.

The three quantities of cell voltage, stack power and temperature are fitted in order to generate a model of the experimental data as a function of the fan voltage and current density. Figure 3a-c show the 3D-plots of the model based on two input variables.

The empirical model used the Robust Neural Networks (RNN) approach automatically suggested by CAMEO as the most suitable model. As can be seen, such a modelling technique is capable of following highly nonlinear trends - as long as enough measurements are available.

The models are created from the 530 points, with the coefficients of determination $R^{2}, R^{2}$ adjusted and $R^{2}$ predicted, higher than 0.99 (Figure 3). This therefore represents an accurate representation of the experimental data.

The maximum power $(131 \mathrm{~W})$ is found for a current density of $0.83 \mathrm{~A} \mathrm{~cm}-2$, a cell voltage of $0.52 \mathrm{~V}$, an operating temperature of $56^{\circ} \mathrm{C}$ and a fan voltage of $10.41 \mathrm{~V}$ (b).

The S-optimal design matrix with 50-5 experiments provides a maximum power within less than 5 $\%$ difference of the initial experimental matrix for all the predicted variables, along with a narrower $95 \%$ confidence interval (Table 1, Figure 8 ). Therefore, the experimental matrix provided by the S-optimal design plan is suitable for a reduction of the number of experiments in similar future tests, yet enables the determination of the maximum power with similar accuracy to the much larger (10 times) experimental matrix.

To the authors' best knowledge, this is the first time the S-Optimal design of experiments has been used to reduce the number of experiments required to map the operations of a fuel cell. Although 
the number of experiments (here 50-5) may potentially vary from one fuel cell system to the next, depending on the level of non-linearity and the ability of the S-Optimal plan to describe it, this methodology is widely applicable to different fuel cell optimisation challenges.

)The use of a large dataset ensures validity of the model and fitting. On the other hand, it makes studying the influence of other variables (e.g. materials, design and hardware alterations) challenging due to the extensive time required ( 8 hours) to capture this map. Therefore, the design of experiment approach can be used to reduce the number of experiments, yet build a model robust enough to predict the same maximum power for the same operating points.

\section{Reduction of the dataset using the DoE}

This section aims to reduce the number of experiments significantly, yet determine the maximum power with $<5 \%$ difference compared with the results determined with the experimental matrix. The $5 \%$ criteria not only applies to the response (power), but also to the two inputs (current density and fan voltage) and the stack temperature, as altogether these parameters will affect the conditions of the fuel cell.

Due to restrictions of the original experimental matrix caused by intrinsic performance limitations of the fuel cell (e.g. it is not possible to operate at a fan voltage of $4 \mathrm{~V}$ and a current density of 0.95 $\mathrm{A} \mathrm{cm}^{-2}$ without leading to overheating and irreversible damage), a central composite design (CCD) is used to account for the curvature of the design space. The CCD for two factors is the combination of a two level experimental plan with a central point, and four points that account for the interaction terms of the polynomial model equation up to $2^{\text {nd }}$ order of the input variables (NIST/SEMATECH, n.d.). Therefore, they can only be fitted with a $2^{\text {nd }}$ order polynomial equation. Altogether, it is composed of 11 points: nine design points, where the first one - in the centre of the domain - is repeated twice. The CCD plan has been used to generate the experimental matrix (DoE Wizard Toolkit, CAMEO) with nine experimental points and two repeats, or the so-called Central Composite Design Matrix. For real experimental data generation, CAMEO would drive a corresponding test bed to run these settings and return the measured data. For this comparison, the 'measurement-data' were taken out of the reference model. The 'measurement noise' in the 
repetition points is generated by using the lower and upper borderline of the 'model prediction interval for $95 \%$.

Specifically for the repetition points (marked in Figure 6), the statistical noise is lower than the deviations of the measurements from the model in the other areas. This observation is expressed in the so-called 'lack of fit'. This means that the model is probably not capable of sufficiently representing the nonlinearity of the unit under test. The Central Composite Design (CCD) is designed to only build $2^{\text {nd }}$ order polynomial models, which is verified in Figure 6.

The maximum power modelled with the CCD differs from the one of the initial experimental matrix (b).

The S-optimal design matrix with 50-5 experiments provides a maximum power within less than 5 $\%$ difference of the initial experimental matrix for all the predicted variables, along with a narrower $95 \%$ confidence interval (Table 1, Figure 8). Therefore, the experimental matrix provided by the S-optimal design plan is suitable for a reduction of the number of experiments in similar future tests, yet enables the determination of the maximum power with similar accuracy to the much larger (10 times) experimental matrix.

To the authors' best knowledge, this is the first time the S-Optimal design of experiments has been used to reduce the number of experiments required to map the operations of a fuel cell. Although the number of experiments (here 50-5) may potentially vary from one fuel cell system to the next, depending on the level of non-linearity and the ability of the S-Optimal plan to describe it, this methodology is widely applicable to different fuel cell optimisation challenges.

). It is $5 \%$ lower, therefore not suitable as defined by our criteria. More importantly, it corresponds to a different operating point (higher current density and lower fan voltage in comparison with the Initial Matrix). This would provide an operating temperature $6{ }^{\circ} \mathrm{C}$ higher, which would not be suitable for operations of the fuel cell. Operations at this modelled maximum power would cause large dehydration in the cell, as it is too hot to maintain liquid water in the cell. The main issue with the CCD plan is that there are not enough experimental points, with some areas of the domain omitted, along with the second order polynomial not being complex enough to provide a suitable fitting. Therefore, a larger design space, alongside a higher order non-linear model is required. 


\section{S-Optimal Design}

The S-optimality criteria ensures that the points throughout the design space are as spread out as possible, yet describes the entire design space, which ensures that non-linearity is detectable by a modelling approach (Das, 2002; Lewis, 2009; Zloklikovits et al., 2008). The S-optimal design plan has been used to generate the experimental matrix (DoE Wizard Toolkit, CAMEO) with 50 experimental points and five repeats, or so-called 50-5 S-Optimal Design Matrix (Figure 7a). The data has been fitted using the Robust Neural-Network (RNN), which is also able to detect nonlinearity appropriately (Figure $7 \mathrm{~b}$ ). The S-Optimal design plan is particularly relevant to describe fuel cells performances. Indeed, this design plan provides the possibility to avoid particular areas of the operational map. This feature is typically observed in fuel cells, whereby operating the fuel cell above a certain current density / fuel and reactant flow rate can potentially lead to irrecoverable performance losses and drastic failures.

As expected, the S-optimal design matrix describes the area much better than the CCD matrix (Figure 7a). Secondly, the RNN models are of much higher quality for the $R^{2}$ predicted than the $2^{\text {nd }}$ order polynomial model, specifically for the cell voltage (Figure $7 b$ ).

The S-optimal design matrix with 50-5 experiments provides a maximum power within less than 5 $\%$ difference of the initial experimental matrix for all the predicted variables, along with a narrower $95 \%$ confidence interval (Table 1, Figure 8 ). Therefore, the experimental matrix provided by the $\mathrm{S}$-optimal design plan is suitable for a reduction of the number of experiments in similar future tests, yet enables the determination of the maximum power with similar accuracy to the much larger (10 times) experimental matrix.

To the authors' best knowledge, this is the first time the S-Optimal design of experiments has been used to reduce the number of experiments required to map the operations of a fuel cell. Although the number of experiments (here 50-5) may potentially vary from one fuel cell system to the next, depending on the level of non-linearity and the ability of the S-Optimal plan to describe it, this methodology is widely applicable to different fuel cell optimisation challenges.

The maximum power point has been determined here, but a further challenge involves how best to get to this point from another location on the operational map. For most applications, it is desirable to get to the maximum power point in as short a time as possible; however, sharp increases in 
temperature, or operation at temperatures outside the recommended range could lead to stack damage or significantly reduce the lifespan of the cell when repeated regularly. Therefore, an optimum pathway across the operational map exists which represents a trade-off between the factors.

3-2 Determination of the optimum pathway to reach the maximum power.

The effect of increasing the current density and fan voltage in a single increment from open circuit to maximum performance is described below (Figure $9 \mathrm{a}-\mathrm{b}$ ).

The maximum power point has been determined here, but a further challenge involves how best to get to this point from another location on the operational map. For most applications, it is desirable to get to the maximum power point in as short a time as possible; however, sharp increases in temperature, or operation at temperatures outside the recommended range could lead to stack damage or significantly reduce the lifespan of the cell when repeated regularly. Therefore, an optimum pathway across the operational map exists which represents a trade-off between the factors.

\section{Pathway generation planning}

In order to approximate the continuous generic pathway, a discrete pathway was created with intermediate steps of current density and fan voltage held for a given time, as the fuel cell behaviour is non-linear with time. A time target was defined, requiring the stack to be operating at maximum power and optimum temperature within $180 \mathrm{~s}$. This rapid start-up time is in agreement with (Gwak and $\mathrm{Ju}, 2015)$. Nevertheless, this target is lower than the DoE targets (30 s). Yet, this large target ensures that different heat patterns can be observed and understood, with the aim of further optimisation(Fuel Cell Technical Team Roadmap, 2013). Such requirement could for instance correspond to the time required in a hybrid battery fuel cell vehicle for the fuel cell to be operating at full power ready to support battery operation, while the battery responded faster to the power spike.

As each step is composed of three variables (current density, fan voltage, step duration), the model has six degrees of freedom for two steps, nine degrees of freedom for three steps, and 12 degrees 
of freedom for four steps. The tests have been restricted to three intermediate steps, in order to limit the number of experiments and still provide enough flexibility on the variables. In addition, the minimum step size for the current density and fan voltage has been defined, in order to avoid operations of the cell in regions leading to stack failure (typically fan voltage below $5 \mathrm{~V}$, and current density above $0.6 \mathrm{~A} \mathrm{~cm}^{-2}$ ).

To avoid steps where the current or the fan voltage reduces in comparison with the previous steps, or where the current or fan voltage reaches a plateau at an intermediate step, and to ensure that the current and fan voltage always increase from one step to the next (as illustrated Figure 10 in the 'Path with backward step', 'Path with current density plateau' and the 'Requested path'), the current density and fan voltage $u$ increments are defined as follows (equation 1-5):

$u_{i}=\operatorname{var}_{u, i}+u_{i-1}$

(Equation 1)

$u_{1}=\operatorname{var}_{u, 1}$

(Equation 2)

where $u$ is either the current density $j$ or fan voltage Vfan, $i$ the actual step $(1,2,3)$, and $v a r_{u}$ the variation of the parameter $u$, generated in CAMEO. The duration of each step $i$, Step $i$ is also generated by CAMEO.

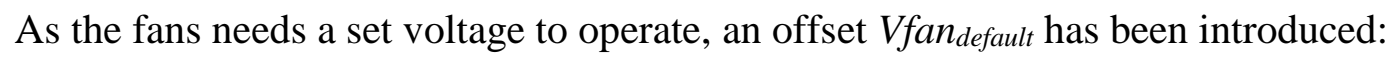

$V f a n_{1}=\operatorname{var}_{V f a n, 1}+$ Vfan ${ }_{\text {default }}$

(Equation 3)

The final step $u_{4}$, where the target performances are reached, is calculated as follows:

$u_{4}=u_{\text {target }}$

(Equation 4)

The duration of each step $i$, Step $_{i}$ is also generated by CAMEO, ensuring that each step is smaller than Step $_{\text {total. }}$ The final Step, Step $_{4}$, is calculated as follows:

Step $_{4}=$ Step $_{\text {total }}-$ Step $_{1}-$ Step $_{2}-$ Step $_{3}$

The dependency of the last Step on the three previous steps, alongside set target parameters (Table 2) reduces the number of variables from 12 to 9.

Finally, the load $I$ is calculated as follows 
$I=j A_{\text {cell }}$

(Equation 6)

with $A_{\text {cell }}$ the cell active area

To ensure the entirety of the restricted domain is described, as fuel cell operation is highly nonlinear, a number of discrete intermediate variations $v a r_{u}$ have been introduced between the minimum and maximum step size for the time, current and fan voltage (Table 3 ).

These steps ensure that there is at least $12 \mathrm{~s}$ at the maximum current and fan voltage, at the minimum conditions the fan voltage is at least $5.1 \mathrm{~V}$, for a minimum current of $0.05 \mathrm{~A} \mathrm{~cm}^{-2}$, that the third step cannot exceed $0.67 \mathrm{~A} \mathrm{~cm}^{-2}$ and the fan voltage does not exceed $10.42 \mathrm{~V}$ at the final step. A plateau in the fan voltage (third step to final step) has been implemented, in order to study the effects of a smoother final temperature increase.

The step matrix and incremental experimental matrix for the 72 experiments are described in Error! Reference source not found. and Error! Reference source not found. of the appendix section and have been generated using CAMEO.

\section{Comparison of the behaviours of three paths using the steps generated by CAMEO}

The behaviour of the cell voltage and temperature through 3 paths, with different CAMEOgenerated intermediates steps (Figure 10 a), can be found below (Figure 11b,) (path 4, 12 and 55). The three paths have completely different thermal behaviours, alongside with a different level of voltage drop in the final step. This indicates the relevance of using intermediates steps, as it enables to tune the temperature gradients and the time taken to reach the steady state performances.

\section{Definition of the key performance indicators (KPIs)}

A key performance indicator (KPI) is a performance measurement that evaluates the success of an experiment. For this path optimisation, the KPIs are calculated via processing of the 72 experiments and extracting key variables. Two KPIs are identified, in order to characterise the efficacy of the responses (cell temperature, cell voltage). Firstly, $\mathrm{KPI}_{1}$ is defined as the time taken for the temperature to reach $50{ }^{\circ} \mathrm{C}$, an indicator of the time necessary to reach steady-state performance. On the other hand, $\mathrm{KPI}_{2}$ is defined to evaluate the heating rate per second over the course of the transition. 


\section{Reproducibility on the two KPIs}

The reproducibility was evaluated by repeating eight paths across the 72 runs, choosing points in the centre of the domain, with every Step lasting 29 s, every variation of current density $v a r_{j}$ of 0.15 $\mathrm{A} \mathrm{cm}^{-2}$, and every variation of fan voltage $\operatorname{var}_{V f a n}$ of $1.12 \mathrm{~V}$. For each path, the KPIs were evaluated and the standard deviation across the eight measurement points calculated

Path 1 consistently provides larger values for $\mathrm{KPI}_{1}$ and $\mathrm{KPI}_{2}$ than the other 7 paths, highlighting that the stack heats up slower initially, which could be due to a gradual conditioning of the cell materials, leading to a larger standard deviation. It is chosen to discard this experiment, as the cell may not be stable in terms of hydration. This leads to much lower standard deviations across the 7 remaining repeats, hence suitable for the model.

\section{Determination of the optimum path}

Three different optimisations strategies are discussed here. Firstly, the most suitable path is to reach $50{ }^{\circ} \mathrm{C}$ as fast as possible in order to reach steady state performance in the shortest time (minimising $\mathrm{KPI}_{1}$ ). At the same time, the second target is to minimise the temperature gradients through the experiments to avoid stress on the materials (minimising $\mathrm{KPI}_{2}$ ). As these two variables are directly correlated in the single step path 0 (Figure 11), this optimisation is only possible with intermediate steps, via modulations of the 9 parameters. The optimisation was achieved using the CAMEO simulation and optimisation toolkit.

The Pareto chart shows that the combined optimisation of both variables, minimisation of $\mathrm{KPI}_{1}$ or minimisation of $\mathrm{KPI}_{2}$, can only be reached via a trade-off that depends on the particular application of the fuel cell and the way in which it is to be operated. For each path, the corresponding nine parameters were generated using CAMEO.

The two local extremes correspond to the points which have the highest $\mathrm{KPI}_{1}$, yet lowest $\mathrm{KPI}_{2}$, and vice-versa. Path 73 provides the worst case scenario, as it reaches performances very fast but with the maximum temperature gradient. This may be useful in applications that are extremely time sensitive, however this is not the target of this optimisation. Similarly, path 75 takes the longest to heat up the cell, yet with the lowest temperature gradient which could reduce strain on the fuel cell's materials. On the other hand, it may take too long to reach a stable operating point. Path 73 
and path 75 are further discussed however, as more than a single point is necessary for the validation, they only highlight extreme cases. Path 74 corresponds to the operating point with the lowest combination of $\mathrm{KPI}_{1}$ and $\mathrm{KPI}_{2}$ (although neither of them have been fully minimised), and therefore is the most suitable candidate for the optimisation study.

\section{Validation results}

In order to validate the accuracy of this model, three predicted paths were measured experimentally (path 73, path 74 and path 75) and their corresponding KPIs calculated and compared with the two predicted KPIs.

The error between measured and predicted has been defined as follows:

Error $=100 \frac{\mid \text { Measured-Predicted } \mid}{\text { Measured }}$

The error is significantly larger for $\mathrm{KPI}_{1}(37 \%)$ than $\mathrm{KPI}_{2}(4 \%)$ for path 73 , slightly larger for path 74 , and within the same range for path 75 .

Altogether, this suggests that more experiments than 64 may have been necessary to appropriately describe the design space, as 2 experiments did not meet the criteria of $50{ }^{\circ} \mathrm{C}$, hence restricting the test-bed to 62 experiments for the model. Nevertheless, the predictions and measured values are within the same range and satisfy the optimisation criteria, even if the values differ.

Further on, the three different paths agree with the trends desired by the model. In path 75 , the temperature gradients are so low that $55^{\circ} \mathrm{C}$ is not reached in $180 \mathrm{~s}$. In opposition, path 73 reaches the optimum the fastest, yet with a high temperature gradient (Figure $13 \mathrm{~b}$ ). Finally path 74 points towards the optimal route, as the voltage reaches quasi steady state in the intermediate states and the temperature gradient does not go above $1.09{ }^{\circ} \mathrm{C} \mathrm{s}^{-1}$.

To further reduce $\mathrm{KPI}_{2}$, the number of intermediate steps may need to be increased to 4 or higher, to increase the number of experiments significantly and fill the design space more extensively. Maybe more KPIs were needed, such as the voltage gradient as soon as the voltage reaches the maximum current density, which would be an indicator of steady state condition. However, this methodology demonstrates the clear advantage of varying multiple parameters at the same time 
instead of optimising each of the 9 parameters separately. Alternatively, it is not impossible that

the target set for $\mathrm{KPI}_{1}, 50{ }^{\circ} \mathrm{C}$, could have been extended to $52{ }^{\circ} \mathrm{C}$ to better describe the change of curve of the temperature as it settles towards $55^{\circ} \mathrm{C}$, which may have provided a better closer agreement between the predicted and measured value, and a start-up time within the DoE targets (below $30 \mathrm{~s}$ ).

Overall, this optimisation study is particularly relevant for powertrains applications. As the requirements from the engine can vary drastically to speed up / slow down the vehicle, the system fuel cell and battery hybrid needs to be able to cope with these changes.

Although, as highlighted in this work, fuel cells do not behave well under abrupt performance changes (Figure 9), the quick, yet controlled increment of the fan voltage and current density presented here enables to operate the fuel cell in a safe manner, while still responding to sharp increases of power requirements. The optimisation methodology provides a method to ensure that heat spikes and drastic voltage decay will be avoided, while reaching the performance targets within acceptable times. Therefore, this extends the fuel cell and overall powertrain system lifetime. Altogether, this type of methodology provides a roadmap to operate fuel cells in powertrains applications, while ensuring that catastrophic failure will be avoided.

\section{Conclusion}

Generating a functional map of fuel cell performance over a range of operating conditions is expensive in terms of resource and time and must be repeated when design or material changes are made. To substantially reduce the experimental effort, it has been shown how DoE can be applied to an air-breathing, open-cathode fuel cell and identify the maximum power point. The CCD design using $2^{\text {nd }}$ order polynomials does not satisfy our criteria for accuracy but the more advanced Soptimal plan in combination with advanced Neuronal Networks provides suitable results to characterise the system with less than $10 \%$ of the experimental effort.

The 'route' taken across an operational map of fuel cell performance is critical for determining overall efficiency, time and durability of a system. Considering the transition from open circuit potential (no load) to maximum power point, a DoE scheme is described and implemented in 
CAMEO that describes the optimal route based on three intermediate steps considering rate of temperature change and time for the transition as the key performance indicators.

More generally, the methodology presented here can be widely used for fuel cells, enabling the determination of the optimum operating 'area' for a given set of parameters throughout an extensive experimental matrix. Once this has been achieved, further studies can use a minimised experimental matrix that satisfies a similar model quality, to study the effect of a different set of parameters. This methodology can be applied to fuel cells, batteries, hybrids and powertrain systems, to optimise for different coupled objectives and reduce the number of experiments to describe the system.

\section{Acknowledgments}

The authors would like to acknowledge the EPSRC for supporting the Electrochemical Innovation Lab through (EP/M009394/1, EP/G030995/1, EP/I037024/1, EP/M014371/1 and EP/M023508/1). PRS acknowledges funding from the Royal Academy of Engineering. The authors would like to acknowledge AVL for their support during the optimization using CAMEO.

\section{References:}

Akyalçın, L., Kaytakoğlu, S.(2008). Optimization of structural combinations on the performance of a PEMFC's MEA. J. Power Sources, Vol 180, pp767-772.

Al-Saleh, M.A., Al-Zakri, A.S., (1998). 'Parametric study of the preparation of gas-diffusion electrodes for alkaline fuel cells by a filtration method. J. Power Sources, Vol 72, pp71-76.

Avl CAMEO - Calibration, All-in-one Powertrain [WWW Document], n.d. URL https://www.avl.com/documents/10138/885965/CAMEO+Flyer+Virtual.pdf/ab206b8f-f5644601-a989-f589cb388857 (accessed 7.17.17).

Bussayajarn, N., Ming, H., Hoong, K.K., Ming Stephen, W.Y., Hwa, C.S. (2009).' Planar air breathing PEMFC with self-humidifying MEA and open cathode geometry design for portable applications'. Int. J. Hydrogen Energy, Vol 34, pp7761-7767.

Chang, K.-Y., Lin, H.-J., Chen, P.-C., (2009). 'The optimal performance estimation for an unknown PEMFC based on the Taguchi method and a generic numerical PEMFC model'. 
Int. J. Hydrogen Energy, Vol 34, pp1990-1998.

Das, A., 2002. 'An introduction to optimality criteria and some results on optimal block design'. Des. Work. Lect. Notes 2, pp1-21.

Endoo, S., Pruksathorn, K., Piumsomboon, P., (2010). 'Identification of the key variables in membrane electrode preparation for PEM fuel cells by a factorial design'. Renew. Energy, Vol 35, pp807-813.

Fabian, T., O’Hayre, R., Litster, S., Prinz, F.B., Santiago, J.G., (2010). 'Passive water management at the cathode of a planar air-breathing proton exchange membrane fuel cell'. $J$. Power Sources, Vol 195, pp3201-3206.

Fuel Cell Technical Team Roadmap, (2013). , U. S. Drive Partnership.

Grujicic, M., Chittajallu, K.M., (2004).' Optimization of the cathode geometry in polymer electrolyte membrane (PEM) fuel cells'. Chem. Eng. Sci., Vol 59, pp5883-5895.

Gwak, G., Ju, H., (2015). 'A rapid start-up strategy for polymer electrolyte fuel cells at subzero temperatures based on control of the operating current density'. Int. J. Hydrogen Energy, Vol 40, pp11989-11997.

Hahn, R., Wagner, S., Schmitz, A., Reichl, H., (2004). 'Development of a planar micro fuel cell with thin film and micro patterning technologies'. J. Power Sources, Vol 131, pp73-78.

Jeong, S.U., Cho, E.A., Kim, H.-J., Lim, T.-H., Oh, I.-H., Kim, S.H., (2006)a. 'A study on cathode structure and water transport in air-breathing PEM fuel cells'. J. Power Sources , Vol 159, pp1089-1094.

Jeong, S.U., Cho, E.A., Kim, H.-J., Lim, T.-H., Oh, I.-H., Kim, S.H., (2006)b. 'Effects of cathode open area and relative humidity on the performance of air-breathing polymer electrolyte membrane fuel cells'. J. Power Sources, Vol 158, pp348-353.

Kim, B., Lee, Y., Woo, A., Kim, Y., 2013. 'Effects of cathode channel size and operating conditions on the performance of air-blowing PEMFCs'. Appl. Energy, Vol 111, pp441-448.

Lewis, P.O., (2008). Optimality Criteria [WWW Document]. URL 
https://v8doc.sas.com/sashtml/qc/chap24/sect30.htm (accessed 6.3.16).

Meyer, Q., Ashton, S., Curnick, O., Reisch, T., Adcock, P., Ronaszegi, K., Robinson, J.B., Brett, D.J.L., (2013). 'Dead-Ended Anode Polymer Electrolyte Fuel Cell Stack Operation Investigated using Electrochemical Impedance Spectroscopy, Off-gas Analysis and Thermal Imaging'. J. Power Sources, Vol 254, pp1-9.

Meyer, Q., Ashton, S., Jervis, R., Finegan, D.P., Boillat, P., Cochet, M., Curnick, O., Reisch, T., Adcock, P., Shearing, P.R., Brett, D.J.L., (2015)a. 'The Hydro-electro-thermal Performance of Air-cooled, Open-cathode Polymer Electrolyte Fuel Cells: Combined Localised Current Density, Temperature and Water Mapping'. Electrochim. Acta, Vol 180, pp307-315.

Meyer, Q., Ashton, S., Torija, S., Gurney, C., Boillat, P., Cochet, M., Engebretsen, E., Finegan, D.P., Adcock, P., Shearing, P.R., Brett, D.J.L., (2016). 'Nitrogen Blanketing and Hydrogen Starvation in Dead-Ended-Anode Polymer Electrolyte Fuel Cells Revealed by HydroElectro-Thermal Analysis'. Electrochim. Acta, Vol 203, pp198-205.

Meyer, Q., Himeur, A., Ashton, S., Curnick, O., Clague, R., Reisch, T., Adcock, P., Shearing, P.R.P.R., Brett, D.J.L.L.D.J.L., (2015)a. 'System-level electro-thermal optimisation of aircooled open-cathode polymer electrolyte fuel cells: Air blower parasitic load and schemes for dynamic operation'. Int. J. Hydrogen Energy, Vol 40, pp1-7.

Meyer, Q., Ronaszegi, K., Pei-June, G., Curnick, O., Ashton, S., Reisch, T., Adcock, P., Shearing, P.R.P.R.P.R., Brett, D.J.L.L.D.J.L., (2015)b. 'Optimisation of air cooled, opencathode fuel cells: Current of lowest resistance and electro-thermal performance mapping'. J. Power Sources, Vol 291, pp261-269.

Meyer, Q., Ronaszegi, K., Robinson, J.,, Noorkami, M., Curnick, O., Ashton, S., Danelyan, A., Reisch, T., Adcock, P., Kraume, R., Shearing, P.R., Brett, D.J.L., (2015)b. 'Combined current and temperature mapping in an air-cooled, open-cathode polymer electrolyte fuel cell under steady-state and dynamic conditions'. J. Power Sources, Vol 297, pp315-322.

NIST/SEMATECH, n.d. NIST/SEMATECH e-Handbook of Statistical Methods [WWW Document]. NIST/SEMATECH E-handb. Stat. Methods. URL http://www.itl.nist.gov/div898/handbook/pri/section3/pri3361.htm (accessed 6.30.14). 
Noorkami, M., Robinson, J.B.J.B., Meyer, Q., Obeisun, O.O.A.O.A., Fraga, E.S.E.S., Reisch, T., Shearing, P.R.P.R., Brett, D.J.L., (2014).' Effect of temperature uncertainty on polymer electrolyte fuel cell performance'. Int. J. Hydrogen Energy, Vol 39, pp1439-1448.

O’Hayre, R., Fabian, T., Litster, S., Prinz, F.B., Santiago, J.G., (2007). 'Engineering model of a passive planar air breathing fuel cell cathode'. J. Power Sources, Vol 167, pp118-129.

Rama, P., Chen, R., Andrews, J., (2008). 'A review of performance degradation and failure modes for hydrogen-fuelled polymer electrolyte fuel cells'. Proc. Inst. Mech. Eng. Part A J. Power Energy, Vol 222, pp421-441.

Rosa, D.T.S., Pinto, D.G., Silva, V.S., Silva, R.A., Rangel, C.M., 2007. 'High performance PEMFC stack with open-cathode at ambient pressure and temperature conditions'. Int. J. Hydrogen Energy, Vol 32, pp 4350-4357.

Sarioglu, I.L., Czapnik, B., Bostanci, E., Klein, O.P., Schröder, H., Küçükay, F., (2014). 'Optimum design of a fuel-cell powertrain based on multiple design criteria'. J. Power Sources, Vol 266, pp7-21.

Sasmito, A.P., Birgersson, E., Lum, K.W., Mujumdar, A.S., (2012). 'Fan selection and stack design for open-cathode polymer electrolyte fuel cell stacks'. Renew. Energy, Vol 37, pp325-332.

Schmitz, A., Tranitz, M., Wagner, S., Hahn, R., Hebling, C., 2003. 'Planar self-breathing fuel cells'. J. Power Sources, Vol 118, pp162-171.

Sutharssan, T., Montalvao, D., Chen, Y.K., Wang, W.-C., Pisac, C., Elemara, H., (2016). 'A review on prognostics and health monitoring of proton exchange membrane fuel cell'. Renew. Sustain. Energy Rev., Vol 75, pp0-1.

Telford, J.K., 2007. 'A Brief Introduction to Design of Experiments'. Johns Hopkins APL Tech. Dig., Vol 27, pp224-232.

Torchio, M.F., Santarelli, M.G., Nicali, A., 2005. 'Experimental analysis of the CHP performance of a PEMFC stack by a 24 factorial design'. J. Power Sources, Vol 149, pp33-43. 
Wahdame, B., Candusso, D., François, X., Harel, F., De Bernardinis, A., Kauffmann, J.-M., Coquery, G., 2007. 'Study of a 5 kW PEMFC Using Experimental Design and Statistical Analysis Techniques'. Fuel Cells, Vol 7, pp47-62.

Wahdame, B., Candusso, D., Francois, X., Harel, F., Kauffmann, J., Coquery, G., (2009). 'Design of experiment techniques for fuel cell characterisation and development'. Int. J. Hydrogen Energy, Vol 34, pp967-980.

Wu, J., Galli, S., Lagana, I., Pozio, A., Monteleone, G., Zi, X., Martin, J., Wang, H., (2009). 'An air-cooled proton exchange membrane fuel cell with combined oxidant and coolant flow'. $J$. Power Sources, Vol 188, pp199-204.

Zloklikovits, T., Ebner, T., Pollak, B., Beidi, C., (2008). 'Automated Shift Quality Calibration on Chassis Dyno calibration technology'. Transm. Conf. 2007, pp1-8. 


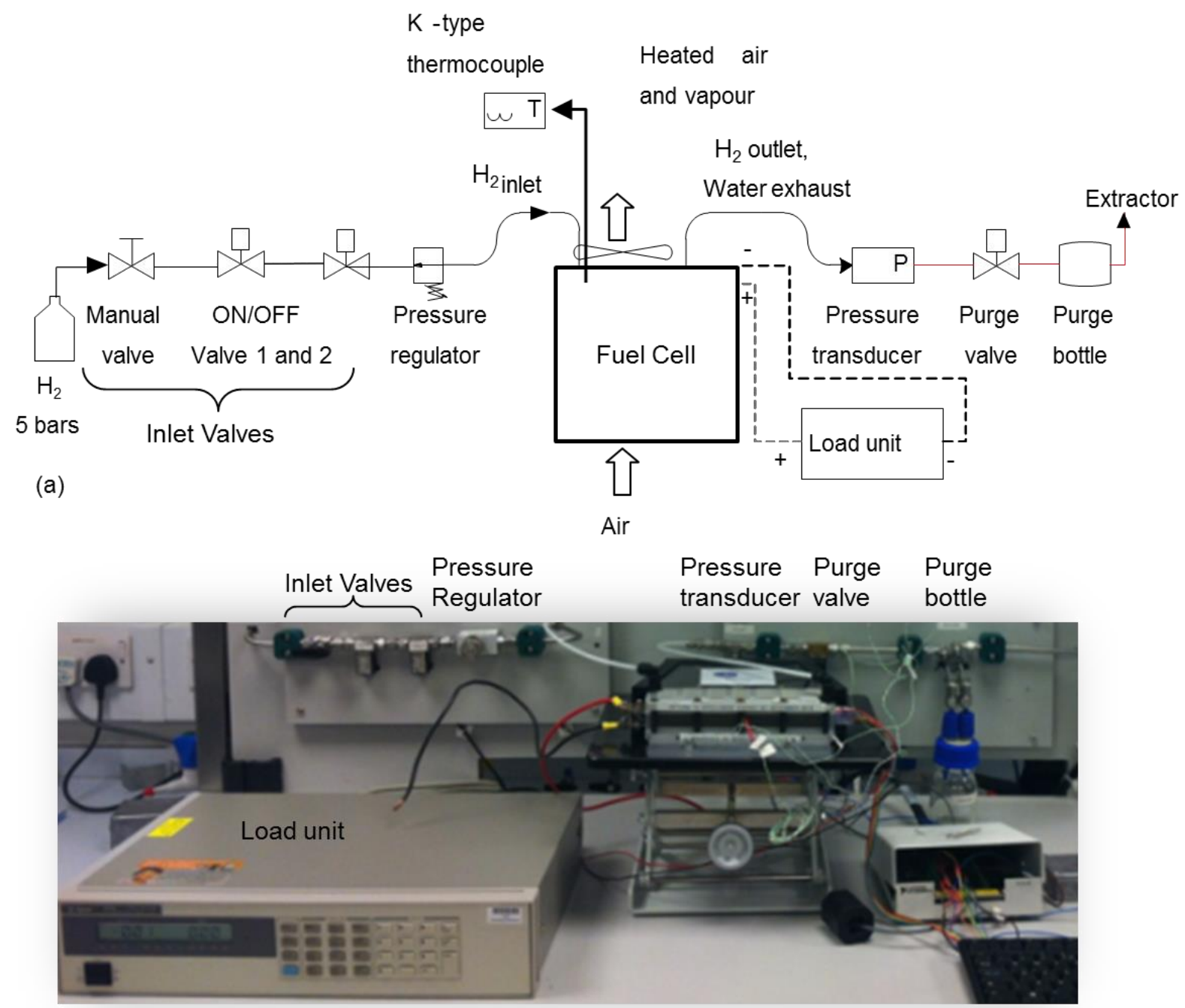

(b)

Figure 1. Process and Instrumentation diagram (P\&ID) (a) and photo (b) of the test station 


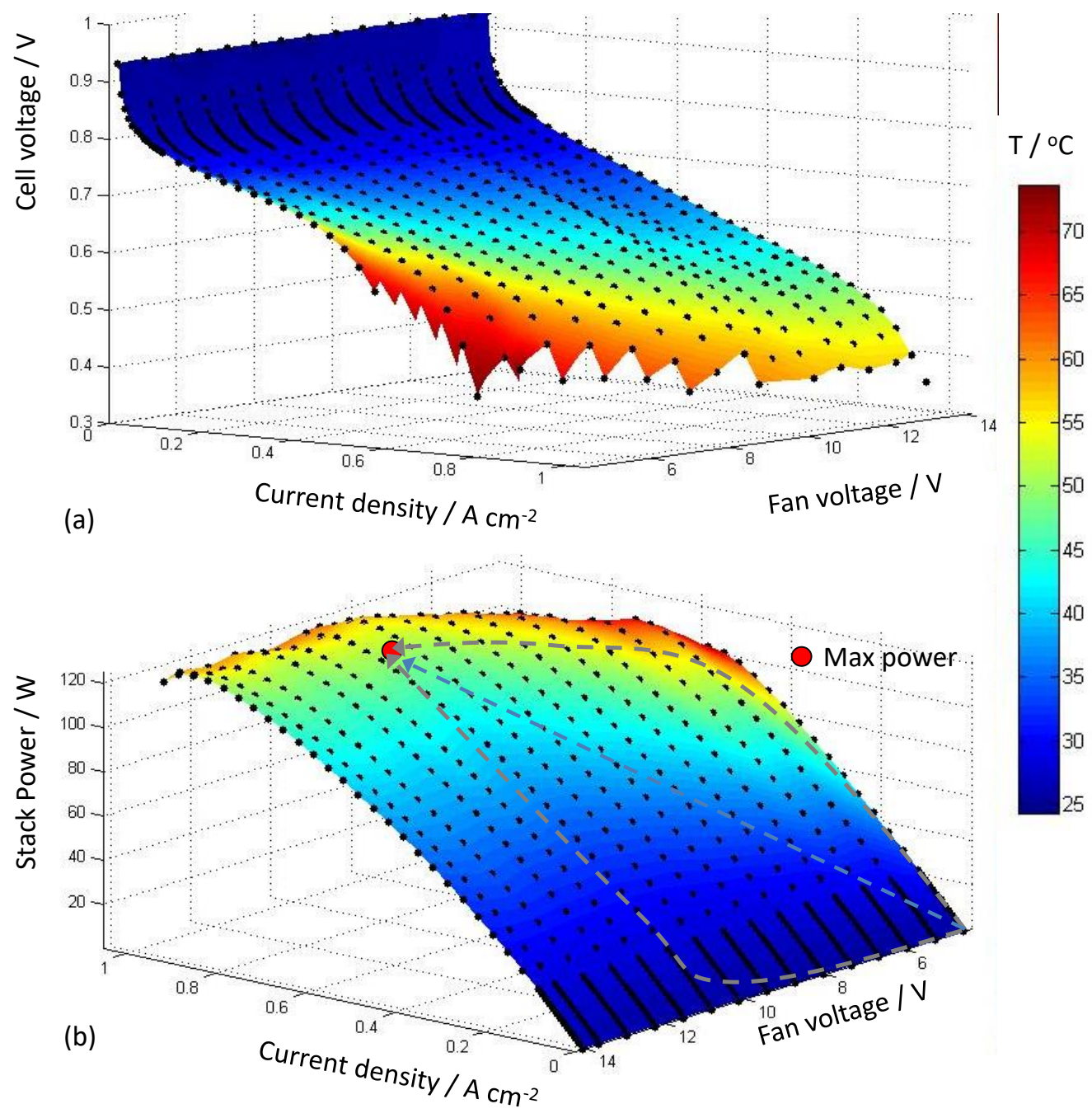

Figure 2. Electro-thermal performance map of the fuel cell, cell voltage (a) and stack power (b), for a fan voltage between 4.5 and $14 \mathrm{~V}$, and a current density between 0 and $1 \mathrm{~A} \mathrm{~cm}^{-2}$. The black lines show examples of the various different paths across the power map to reach the maximum power. 


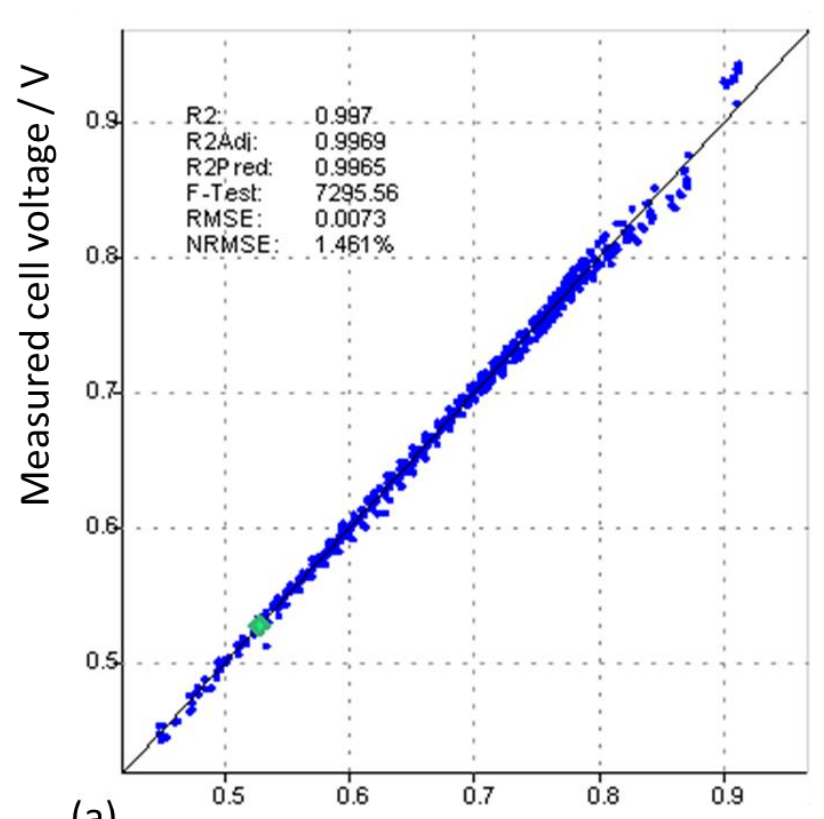

(a)

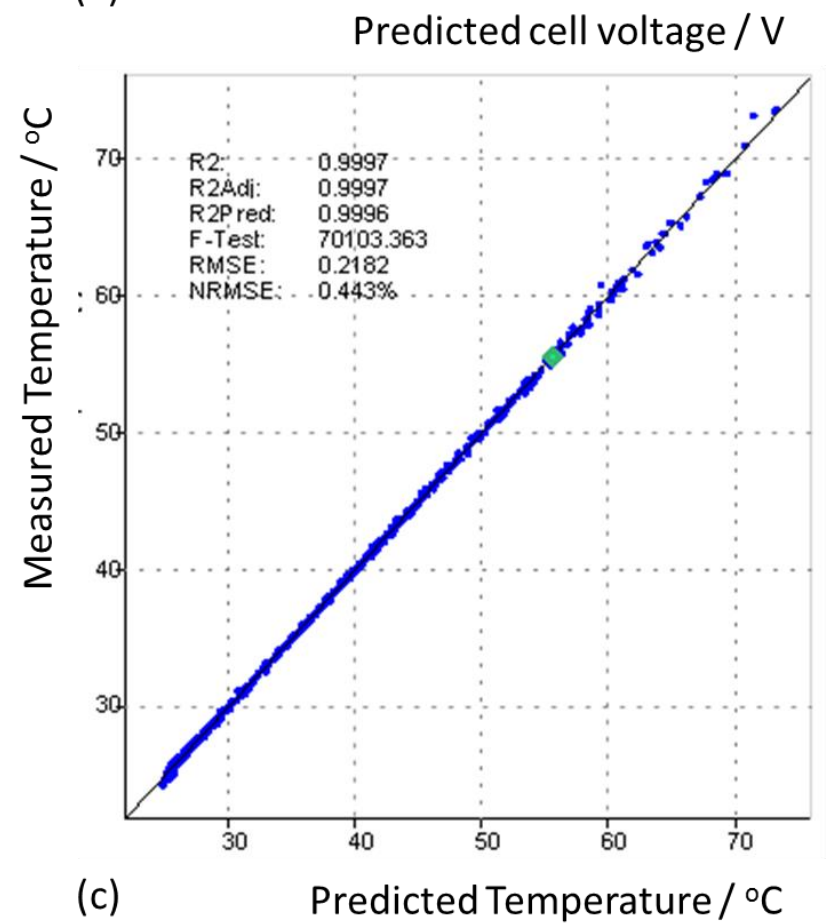

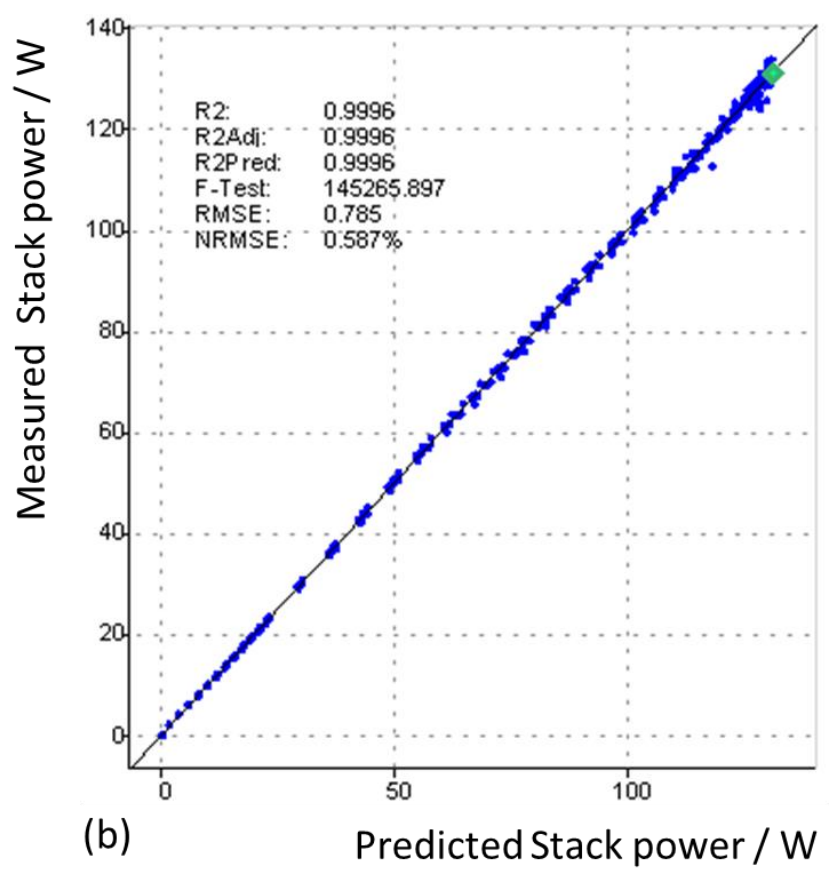

(b)

\section{Predicted Stack power / W}

Figure 3. "Measured versus Predicted plot" for the reference models, cell voltage (a), stack power (b) and temperature (c) using CAMEO, over the 530 points. 


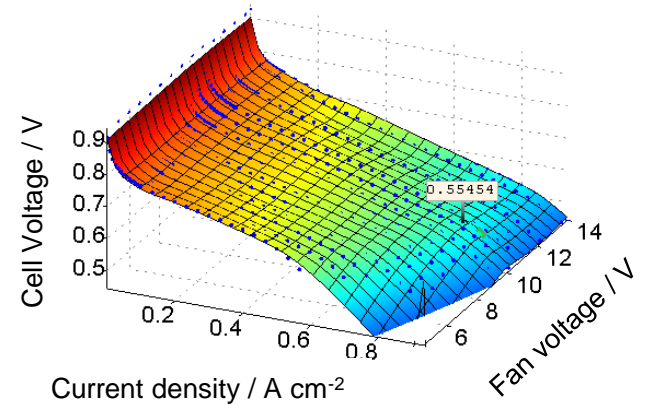

(a)

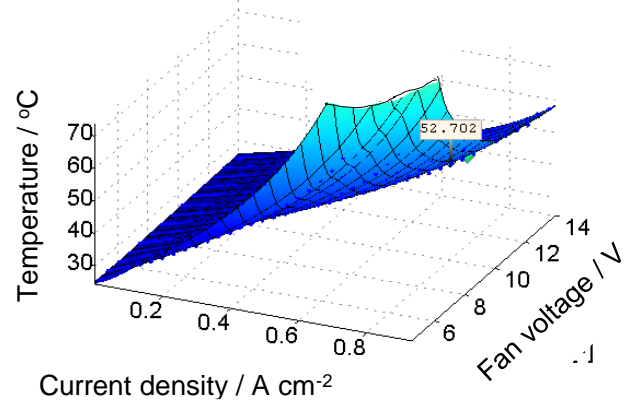

(c)

Figure 4. Plots of the modelled cell voltage (a), power (b) and temperature (c) using the full experimental matrix.

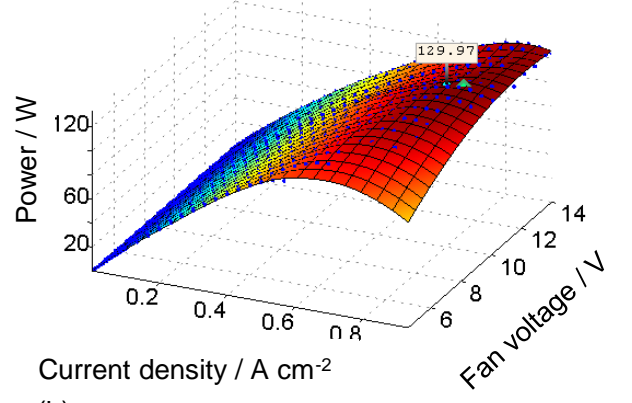

(b) 

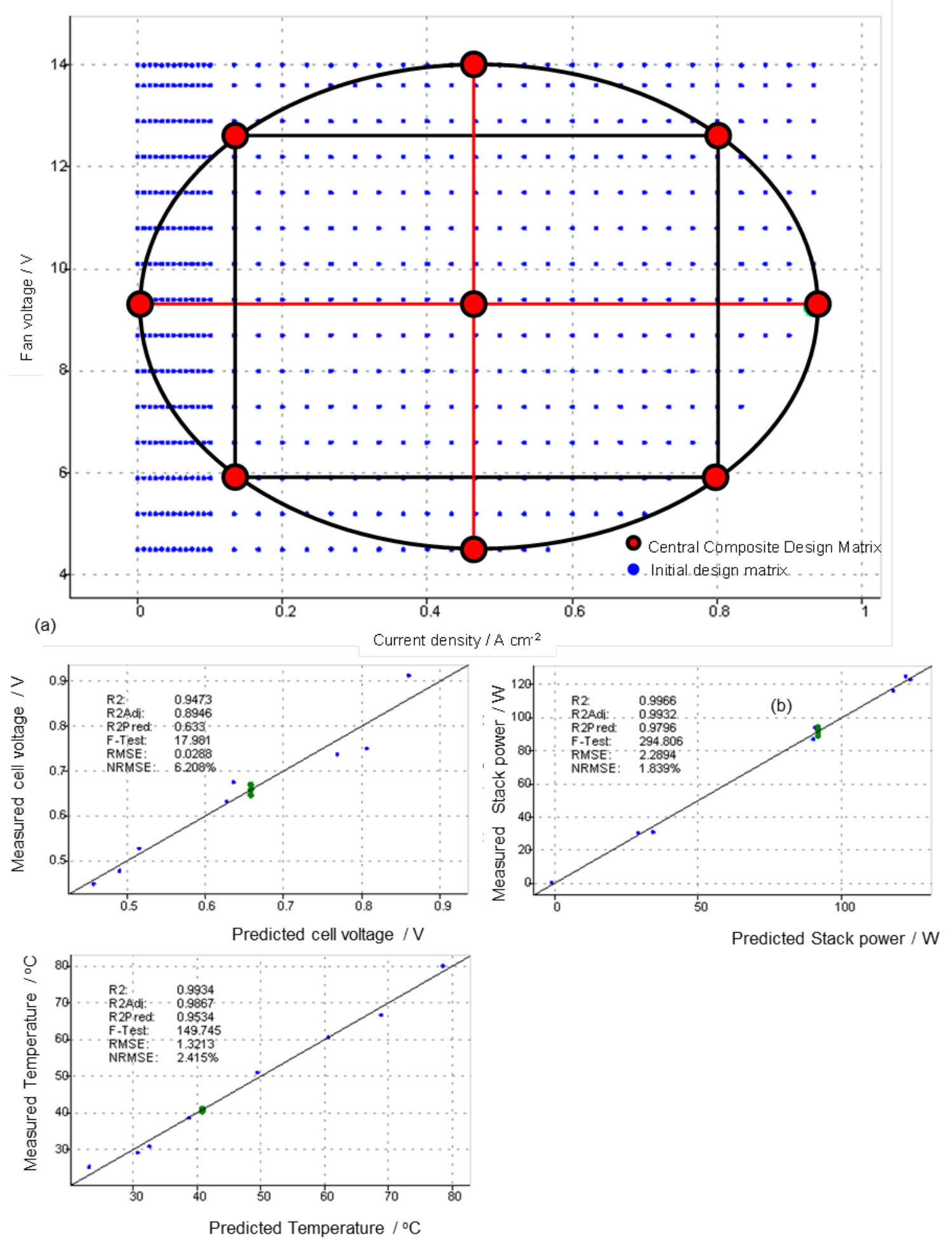

(b)

Figure 5. (a) Initial design matrix (blue) and Central Composite Design matrix (CCD) (red), (b) measured versus predicted plot for $2^{\text {nd }}$ order models generated out of the CCD plan with nine design points plus two repetitions for cell voltage, stack power and temperature. 


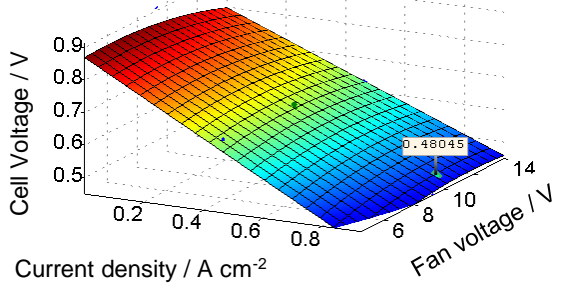

(a)

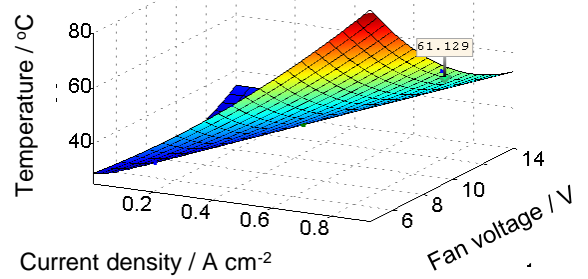

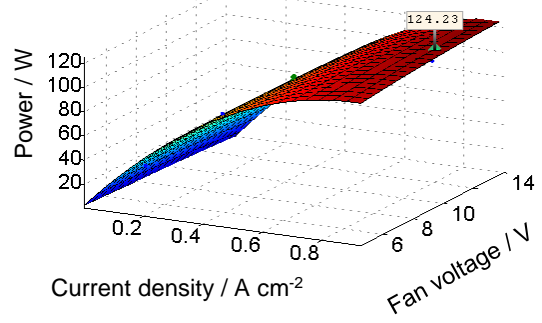

(b)

Figure 6. $2^{\text {nd }}$ Order Polynomial models for cell voltage (a), power (b) and temperature (c) using the CCD with 9-2 points. 

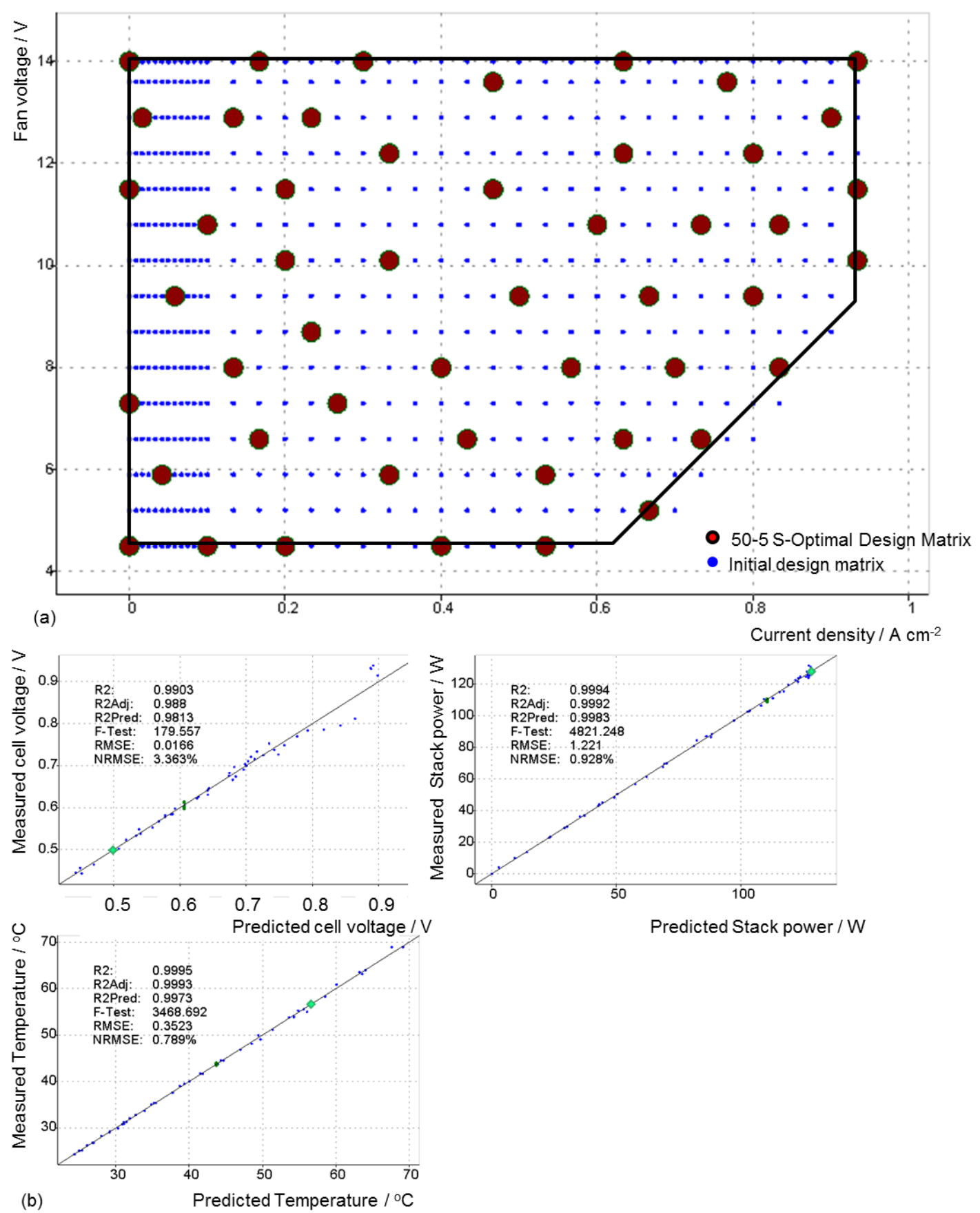

Figure 7. (a) Initial design matrix (blue) and S-optimal design matrix (red), (b) Measured versus Predicted plot for RNN models generated out of the S-optimal plan with 50 design points plus five repetitions for the cell voltage, stack power and temperature. 


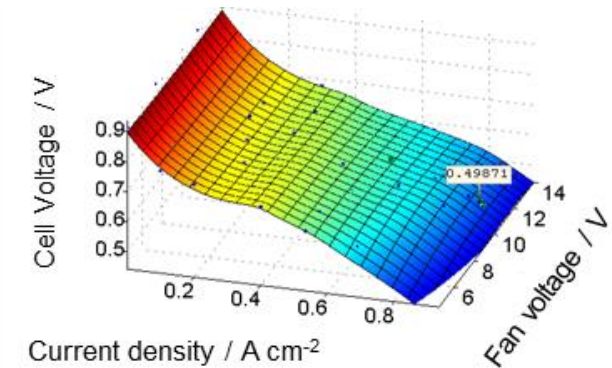

(a)

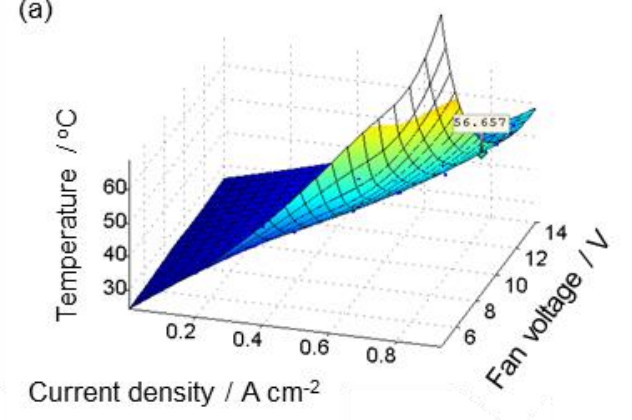

(c)

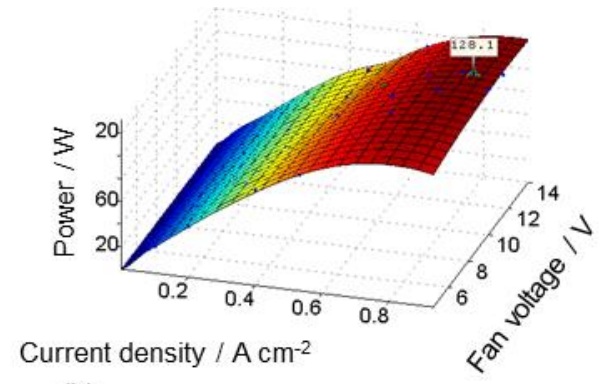

(b)

Figure 8. RNN-models for cell voltage (a), power (b) and temperature (c) using the S-optimal design with 55 points only. 


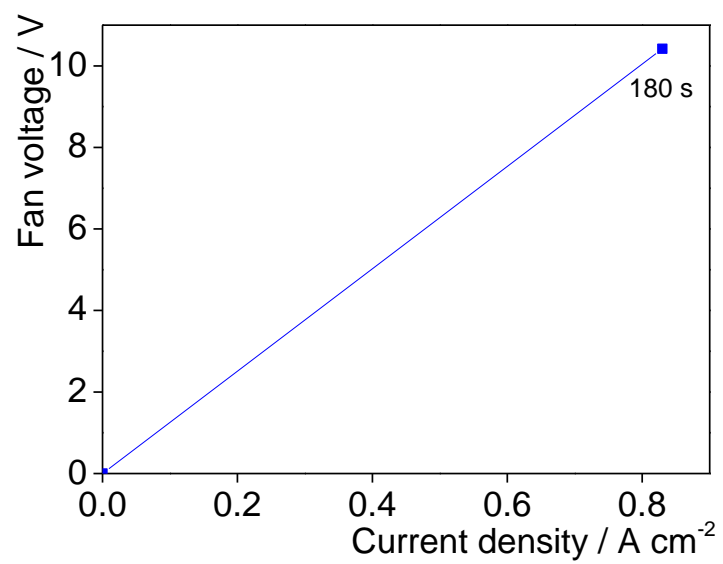

(a)

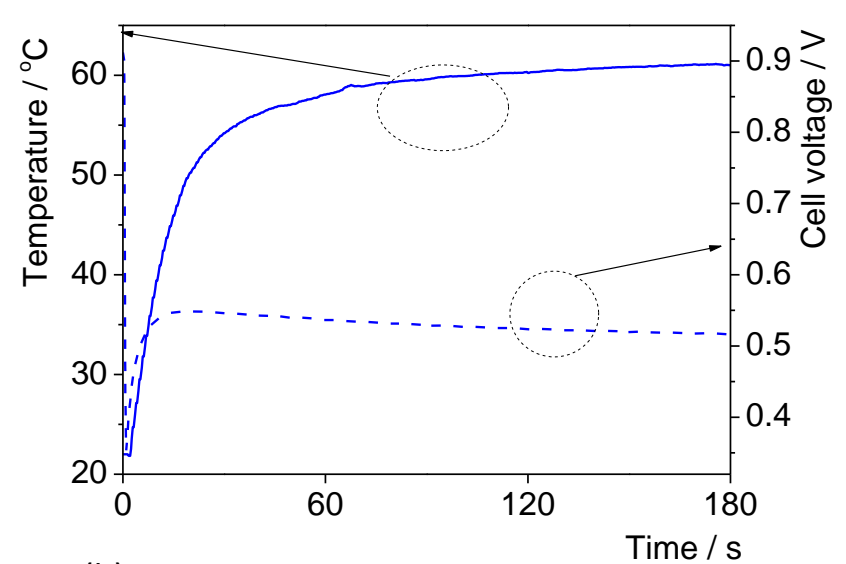

(b)

Figure 9. Electro-thermal performance for path 0 for the cell voltage. (a) Path description, with the Step duration added on the dot. (b) Electro-thermal performance over time, the dash lines are for the cell voltage, the full lines the temperature.

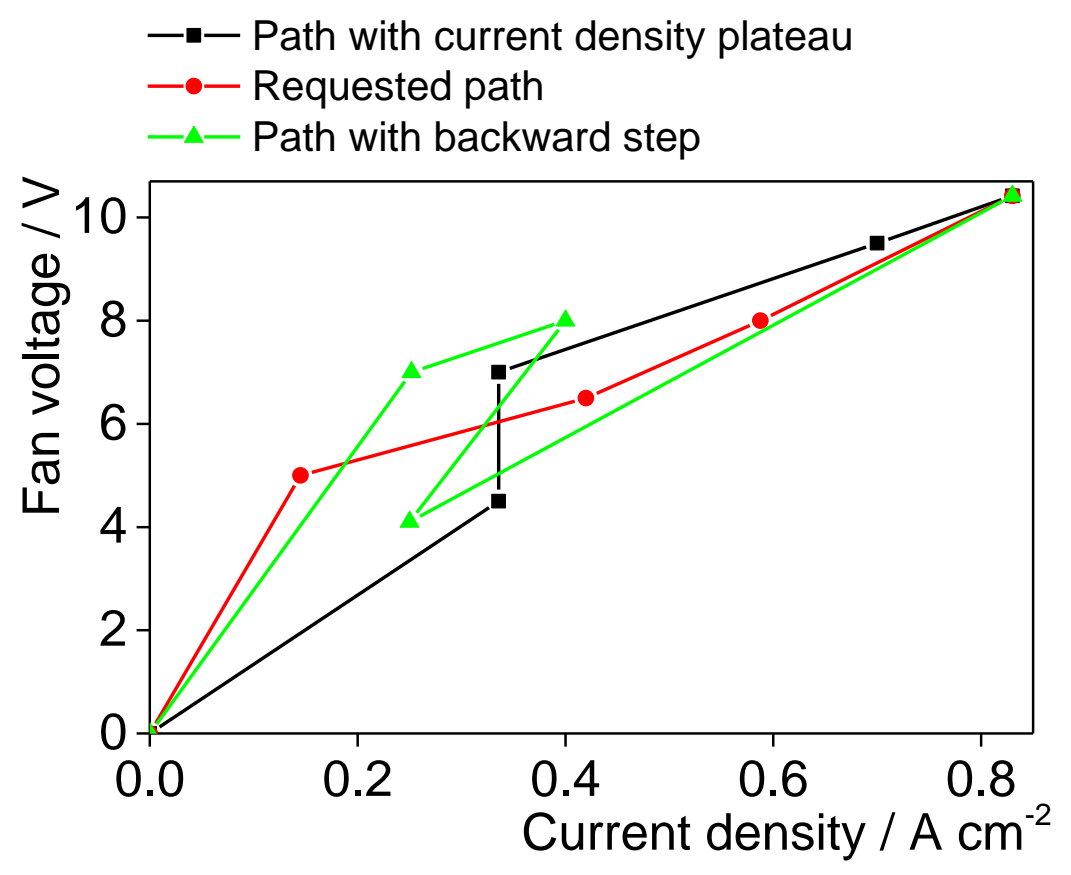

Figure 10. Path with current density plateau, requested path and path with backward step. 

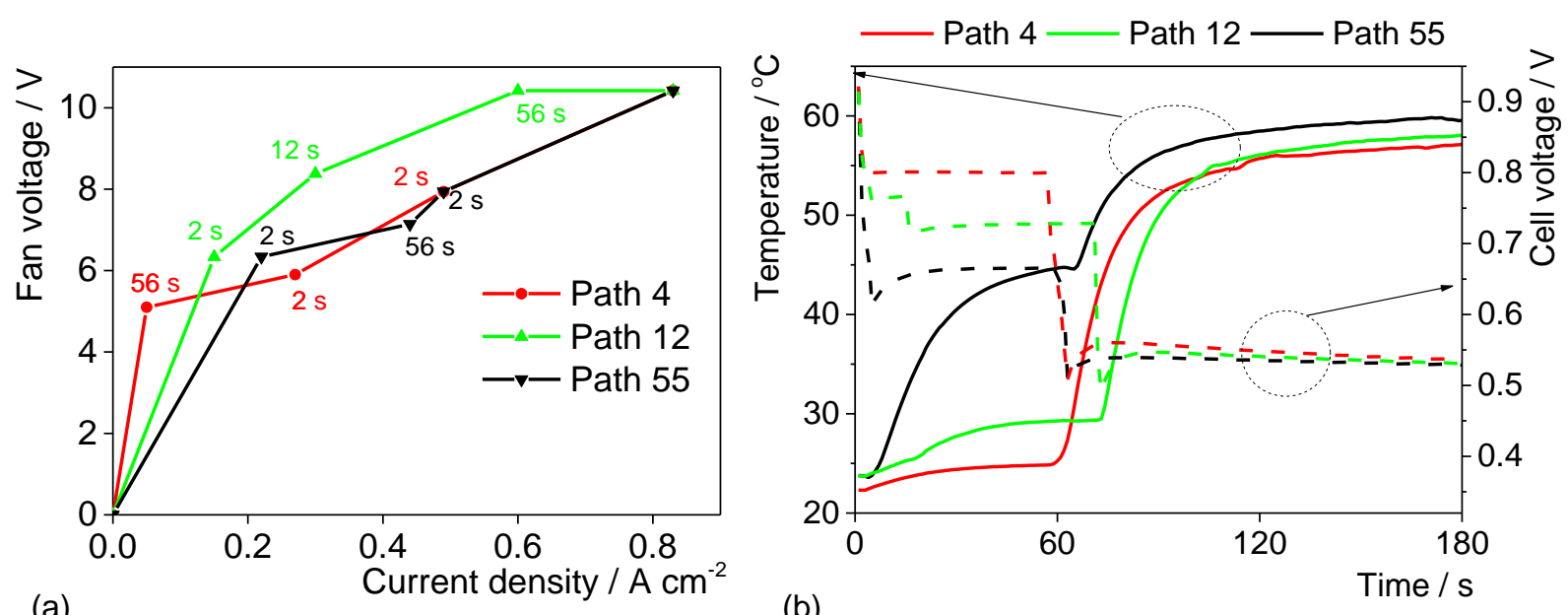

Figure 11. Electro-thermal performance for path 4, path 12 and path 55 for the cell voltage. (a) Path description, with the Step duration added on each dot. (b) Electro-thermal performance over time, the dash lines are for the cell voltage, the full lines the temperature. 


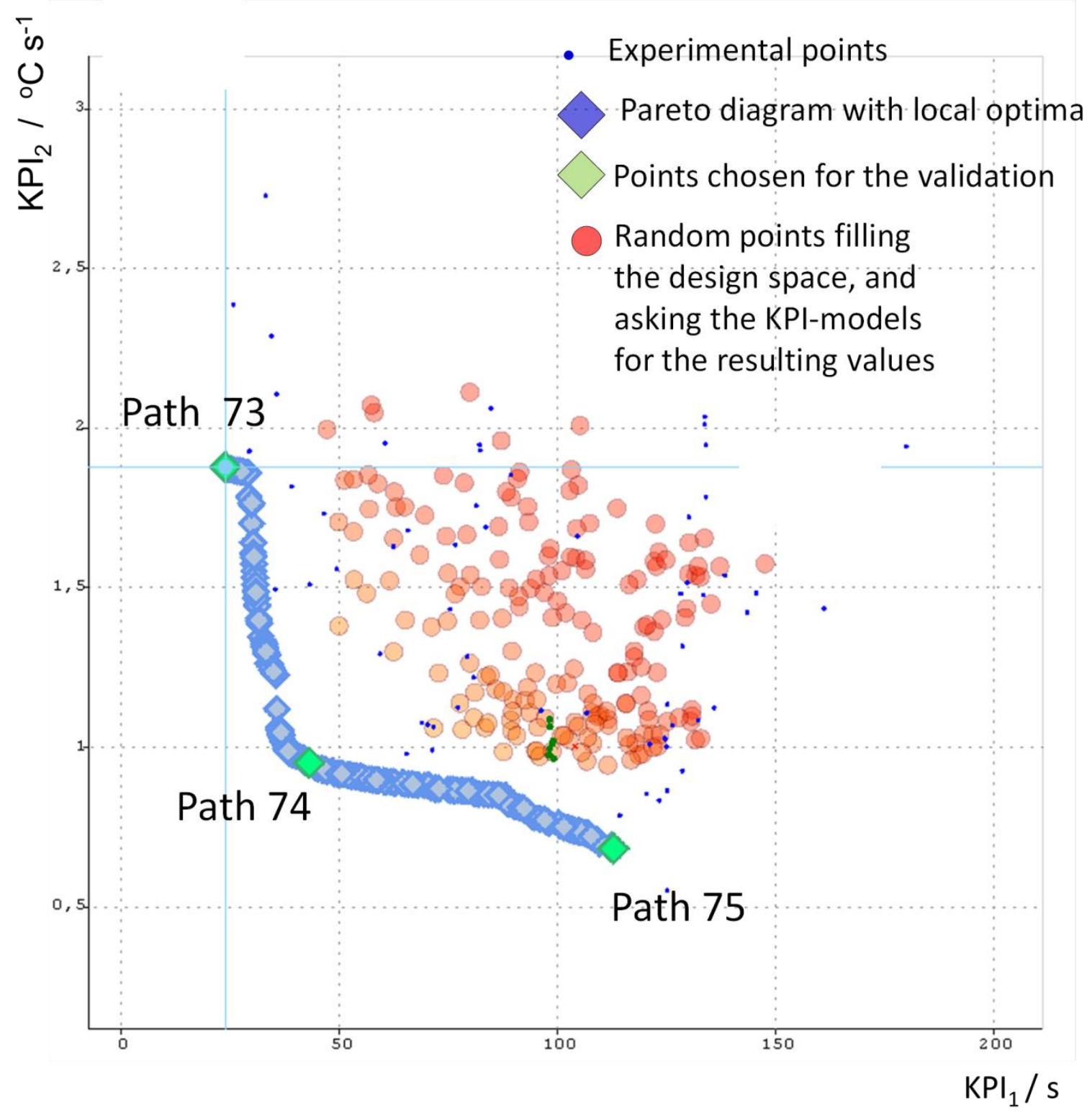

Figure 12. Pareto chart describing the combined minimisation of $\mathrm{KPI}_{1}$ and $\mathrm{KPI}_{2}$, generated using CAMEO, and the experimental points in the domain and the random points filling the design space using the model. 

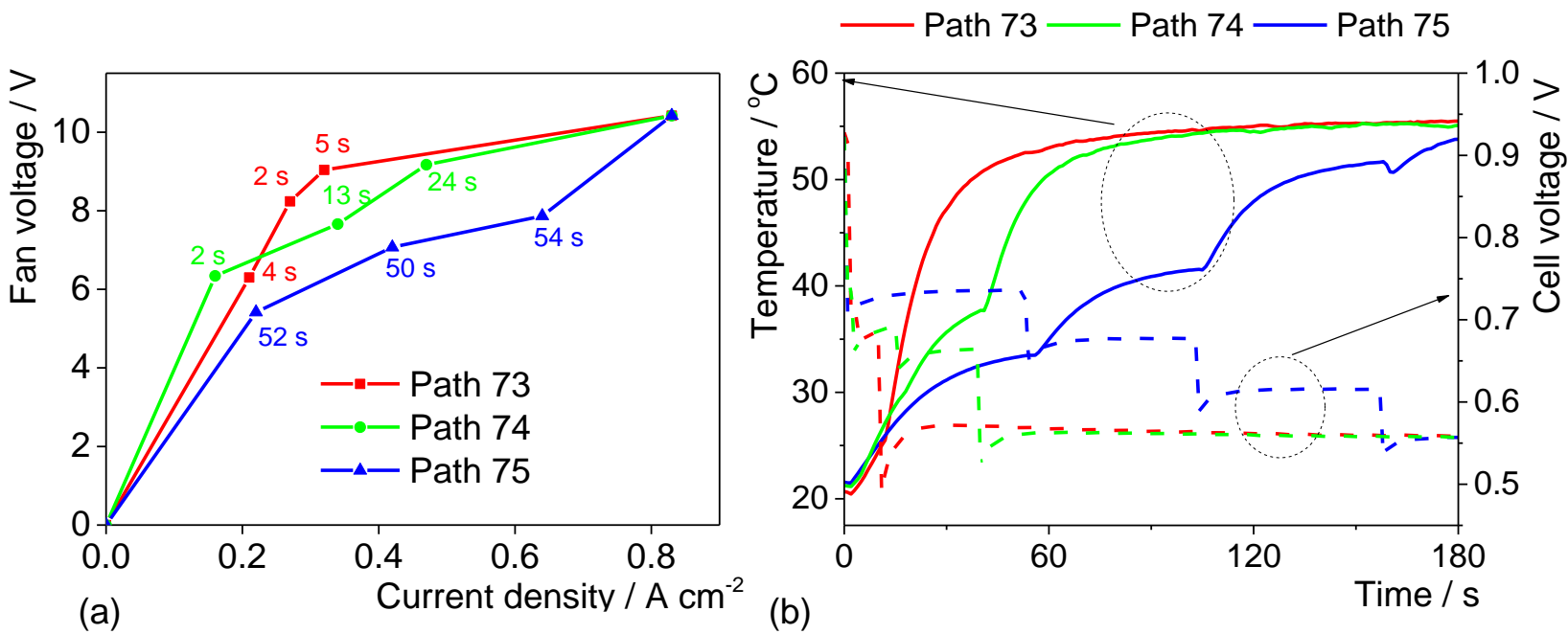

Figure 13. Electro-thermal performance for path 73, path 74, path 75 for the cell voltage and temperature. (a) Path description, with the Step duration added on each dot. (b) Electro-thermal performance against time, the dash lines are for the cell voltage, the full lines the temperature. 
Table 1. Modelled maximum power using the initial experimental matrix, CCD matrix and Soptimal matrix

\begin{tabular}{|l|l|l|l|l|l|}
\hline & $\begin{array}{l}\text { Maximum } \\
\text { power / } \mathrm{W}\end{array}$ & $\begin{array}{l}\text { Temperature } \\
{ }^{\circ} \mathrm{C}\end{array}$ & $\begin{array}{l}\text { Cell Voltage / } \\
\mathrm{V}\end{array}$ & $\begin{array}{l}\text { Current } \\
\text { density / } \\
\mathrm{cm}^{-2}\end{array}$ & $\begin{array}{l}\text { Fan Voltage } \\
/ \mathrm{V}\end{array}$ \\
\hline $\begin{array}{l}\text { Initial } \\
\text { experimental } \\
\text { matrix } 530 \\
\text { points) }\end{array}$ & $131 \pm 0.5$ & $55.5 \pm 0.1$ & $0.52 \pm 0.002$ & 0.83 & 10.41 \\
\hline $\begin{array}{l}\text { CCD matrix }(9 \\
\text { points+2 } \\
\text { repetitions) }\end{array}$ & $124 \pm 6.21$ & $61 \pm 3.58$ & $0.48 \pm 0.08$ & 0.89 & 10.26 \\
\hline $\begin{array}{l}\text { S-Optimal } \\
\text { matrix } \\
\text { points }+50 \\
\text { repetitions) }\end{array}$ & $128.1 \pm 1.3$ & $56.6 \pm 0.35$ & $0.49 \pm 0.009$ & 0.86 & 10.85 \\
\hline
\end{tabular}

Table 2. Physical constants used for the calculations of the increments steps

\begin{tabular}{|l|l|}
\hline Parameter & Value \\
\hline Total experiment time, Step total & $180 \mathrm{~s}$ \\
\hline Target current density, $j_{\text {target }}$ & $0.83 \mathrm{~A} \mathrm{~cm}^{-2}$ \\
\hline Target fan voltage, Vfan $_{\text {target }}$ & $10.42 \mathrm{~V}$ \\
\hline Minimum fan voltage, Vfan $_{\text {default }}$ & $4.3 \mathrm{~V}$ \\
\hline Cell active area, $A_{\text {cell }}$ & $60 \mathrm{~cm}^{2}$ \\
\hline
\end{tabular}


Table 3. Intermediate steps in the domain. The three columns are not correlated.

\begin{tabular}{|c|c|c|}
\hline Step duration / s & $V a r_{j} / \mathrm{A} \mathrm{cm}^{-2}$ & $\operatorname{Var}_{V f a n} / \mathrm{V}$ \\
\hline 2 & 0.05 & 0.8 \\
\hline 12 & 0.1 & 1.12 \\
\hline 29 & 0.15 & 1.6 \\
\hline 37 & 0.19 & 2.04 \\
\hline 48 & 0.22 & \\
\hline 56 & & \\
\hline
\end{tabular}

Table 4. KPIs for eight repeats of Path 1 throughout the test and standard deviations

\begin{tabular}{|c|c|c|c|}
\hline \multicolumn{2}{|l|}{ Path } & $\mathrm{KPI}_{1} / \mathrm{s}$ & $\mathrm{KPI}_{2} /{ }^{\circ} \mathrm{C} \mathrm{s}^{-1}$ \\
\hline \multirow{8}{*}{ Repeats of path 1} & 1 & 104.119 & 1.00328 \\
\hline & 11 & 99.1640 & 0.96523 \\
\hline & 21 & 98.1381 & 0.97712 \\
\hline & 31 & 98.2485 & 1.0876 \\
\hline & 41 & 98.3584 & 0.99703 \\
\hline & 51 & 98.39258 & 1.06592 \\
\hline & 61 & 99.1 & 1.02046 \\
\hline & 72 & 98.90234 & 1.01244 \\
\hline \multicolumn{2}{|l|}{ Standard deviation } & 1.857563 & 0.039148 \\
\hline \multicolumn{2}{|c|}{ Standard deviation excluding path 1} & 0.395732 & 0.041527 \\
\hline
\end{tabular}

Table 5. Predicted and measured KPIs for path 73, path 74 and path 75. 


\begin{tabular}{|l|l|l|l|l|l|l|}
\hline & \multicolumn{5}{|l|}{$\mathrm{KPI}_{1} / \mathrm{s}$} & \multicolumn{2}{l|}{$\mathrm{KPI}_{2} /{ }^{\circ} \mathrm{C} \mathrm{s}^{-1}$} \\
\cline { 2 - 7 } & Predicted & Measured & Error $/ \%$ & Predicted & Measured & Error / \% \\
\hline Path 73 & 24 & 38.11 & 37 & 1.87 & 1.95 & 4.1 \\
\hline Path 74 & 43.2 & 59 & 26 & 0.95 & 1.09 & 12.8 \\
\hline Path 75 & 112 & 133 & 15 & 0.68 & 0.58 & 17 \\
\hline
\end{tabular}

